\title{
Cultura e política: lições de análise
}

P OUCOS livros fizeram uma leitura tão densa e tão aguda sobre as relações entre cultura e política na Europa moderna e contemporânea quanto $O$ medo dos bárbaros: para além do choque das civilizações, de Tzvetan Todorov. Poucos livros revelaram de forma tão nítida como determinados discursos constroem visões acerca do "Outro" e as consequências políticas dessa operação. Poucos livros foram tão explícitos no esclarecimento dos condicionantes da nova dinâmica geopolítica após a guerra gria e o 11 de Setembro.

Inicio assim esta resenha para que o leitor seja impelido a discutir as corajosas teses defendidas por Todorov. De fato, ainda que o subtítulo evoque o polêmico livro de Samuel Huntington como ponto de partida de sua reflexão, talvez o que mais incomode o autor (e a razão que o levou a intervir nesse debate) seja o contexto assaz tenso vivido na França a partir, sobretudo, da década de 1990 e agravado pelo governo Sarkozy envolvendo os supostos "nativos" e os imigrantes oriundos das ex-colônias francesas na África. Nascido na Hungria e radicado no Hexágono desde 1963, Todorov possui uma visão "desterritorializada" que certamente favoreceu parte do desenvolvimento de sua argumentação. Com isso, não quero dizer que autores nascidos na França sejam incapazes de produzir críticas ao seu próprio país, como se houvesse um "determinismo geográfico-intelectual”. Muito pelo contrário: A quoi sert l'identité nationale, de Gérard Noiriel (escrito em 2007 no mesmo contexto e com moti- vações e objetivos muito parecidos aos de Todorov), é um belo exemplo de voz "autóctone" dissonante ante os rumos da política de imigração de Sarkozy e a avaliação negativa de parte da população francesa a negros e muçulmanos por essa razão, não consigo entender a ausência de Noiriel na bibliografia. No entanto, como geógrafo, ou seja, como alguém que parte do pressuposto de que existe uma articulação indissociável entre o lugar e a produção do discurso, preciso atentar para o fato de que a dupla experiência (franco-húngara) vivida por Todorov atua no sentido de favorecer a tolerância diante da alteridade.

$\mathrm{Na}$ verdade, esse é um de seus principais argumentos em prol de uma Europa que saiba respeitar as minorias e as diferenças: a própria história de constituição do continente mostra que ele é, por excelência, diverso, e que as tentativas anteriores de edificação de impérios soberanos malograram, cedendo lugar a um acordo no qual o autor deposita suas esperanças: a União Europeia. Para ele, trata-se de um grande avanço. A unidade e a identidade europeias assentar-se-ão, exatamente, sob sua pluralidade.

A União Européia é composta por numerosos países, cada um dos quais está dividido, por seu turno, entre forças políticas opostas. Uma informação revelada na Itália dificilmente vai passar despercebida na França ou na Alemanha e reciprocamente. Neste aspecto, a pluralidade está a serviço da concorrência e, por isso mesmo, da verdade. (p.214)

A pluralidade, portanto, possui um 
componente epistemológico cujo desdobramento político é crucial. É nisso que o autor investe do início ao fim do livro: conceitos como civilização, barbárie, cultura, religião, ocidente, oriente, islamismo e identidade nacional vão sendo implodidos aos poucos - numa démarche que lembra um pouco o desconstrucionismo de Derrida, embora o filósofo não seja citado -, questionados por serem pilares de discursos cujas implicações práticas são precisamente guerras, terrorismos, xenofobia, assassinatos em massa... Se houvesse mesmo um choque entre civilizações, esse jamais teria fim, diz Todorov, posto que elas possuem traços irredutíveis e, não raro, inconciliáveis. Incapazes de distinguir o Islã (religião multissecular) do islamismo (movimento político fundamentado na religião islâmica), ao aventarem a existência de uma guerra religiosa, leituras como as de Huntington, Oriana Fallaci e Élie Barnavi não fazem outra coisa senão alimentar e fortalecer organizações como a Al-Qaeda. É nesse sentido que as teses de Huntington foram prontamente aceitas por... Bin Laden! (p.109).

Se, em vez do diálogo sincero, do reconhecimento da alteridade e da coexistência entre minorias e maiorias, for decretada a "racionalidade" de uma crença ante outra (tal como sugeria a conferência de Bento XVI em Regensburg, provocando enorme mal-estar junto às nações adeptas de Maomé [p.176-7]); se intervenções militares continuarem sendo aceitas em nome do "mundo livre" (vide os Estados Unidos no Iraque e no Afeganistão); e se o governo francês insistir em impor sua "língua" e seus "valores", ignorando os árabes e seu modo de vida no território do Hexágono (algo que eles mesmos provocaram via colo- nialismo!), então nos veremos rodeados de fanatismo religioso, atentado às embaixadas norte-americanas, homensbomba e banlienes (periferias) inflamadas ao redor do globo. Não se combate a barbárie com a barbárie (p.130) e tampouco com uma oposição simplória civilização versus barbárie. Das cruzadas ao colonialismo e às guerras mundiais, $\mathrm{o}$ passado europeu não autoriza um presente de intransigência e medo.

Todorov faz um apelo à responsabilidade de Estados-Nação, religiosos, políticos, mídia, formadores de opinião e cidadãos em geral. $\mathrm{Na}$ realidade, todos têm uma dívida com a história, impossível de ser dividida por uma fronteira onde o Ocidente é o bem e o Islã é o mal. Ora, o que dizer da aceitação da tortura pelo governo da América do Norte, seja no próprio território, seja em Abu Ghraib? Ou da criação de um Ministério da Identidade Nacional por Sarkozy?

A intolerância parece estar na raiz de uma série de conflitos internacionais, e é exatamente contra isso que Todorov investe todas as suas forças. A associação maniqueísta envolvendo cultura e política engendra um verdadeiro campo minado onde, no frigir dos ovos, ninguém sai ganhando. Destarte, um dos momentos mais inquietantes do livro é o capítulo 4 - "Navegar entre arrecifes" - onde, tecendo seus raciocínios no fio da navalha, problematiza aquela que é uma das bases do Estado democrático: a liberdade de expressão. É evidente que nosso resenhado não advoga a favor de sua supressão, mas o que ele destaca são os desdobramentos explosivos advindos de palavras e ações nem sempre tão responsáveis assim. Casos como as caricaturas ridicularizando Maomé publicadas no mais influente diário dinamarquês 


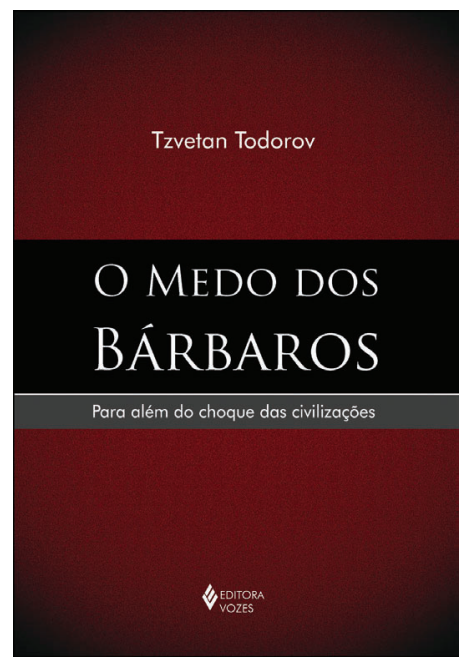

TODOROV, T. O medo dos bárbaros: para além do choque das civilizações. Petrópolis: Vozes, 2010. 237p.

em 2005 e reproduzidas no semanário satírico francês Charlie-Hebdo no ano seguinte, bem como a injúria antimuçulmana de um professor francês no $L e$ Figaro e tudo aquilo que elas geraram em termos de tensões sociais e internacionais (com a globalização e a internet tudo é mundial e ao vivo) o conduzem a pensar que

Se houvesse, realmente, a vontade de comprovar que a liberdade de expressão é boa em si, qualquer que seja o conteúdo apresentado, teria sido necessário escolher afirmações que fossem ao encontro da opinião comum e que transgredissem proibições aceitas pela maioria dos cidadãos: por exemplo, proferir frases antissemitas. Se ninguém tem a ideia de defender a liberdade de expressão dessa maneira é porque, contrariamente ao que se ouve em determinadas tomadas de posição, essa liberdade não é o único, nem o mais fundamental, dos valores de uma demo- cracia liberal; seu lugar está garantido entre eles, certamente, mas ao lado de outros aos quais ela deveria adaptar-se. Todos aceitam tacitamente tal hierarquia; além disso, não se fala de censura quando se proíbe a incitação ao ódio racial. (p.162, grifo nosso)

Polêmico, não? Aliás, o livro é todo assim, e é exatamente isso que o torna tão pertinente, num mundo em que brados reacionários e conservadores in-sistem em se levantar. No entanto, o sentido do polêmico, aqui, está ligado ao espírito dialógico, argumentativo e racional típico das Luzes - tradição à qual o autor, dialogando com Hume, Kant, Montesquieu e Rousseau, está diretamente vinculado. Para ele, se existe uma identidade na qual a União Europeia deveria reivindicar, essa seria a do Iluminismo (p.205). Ora, ainda que Todorov tenha uma visão assaz crítica da história da Europa, sua démarche passa ao largo do que vem sendo edificado sob a alcunha de "pós-colonialismo" ou, mais recentemente, "epistemologias do sul". No último capítulo - "A identidade europeia" -, uma interpretação mais rigorosa sustentaria que ele continua vendo a Europa como o centro do mundo, sendo, portanto, incapaz de um olhar descentrado e pluritópico que caracteriza o pensamento de Walter Mignolo ou Boaventura de Souza Santos, por exemplo. Ao insistir que a Europa precisa saber integrar as diferenças entre seus vizinhos internos e entre estrangeiros no seu território e que os Estados Unidos devem abdicar do uso preventivo da força, conclui que

a Europa assumiria cada vez mais o papel do que designo por "potência tranquila", ou seja, uma potência desprovida de qualquer projeto imperial, 
sem renunciar, de modo algum, à capacidade de enfrentar o adversário para se defender. Ela deveria dispor de uma força militar porque o mundo nunca será definitivamente pacificado; além disso, tal força deveria estar sob a alçada da própria União Européia, porque seus interesses não coincidem com aqueles que possam ser defendidos por qualquer outra região do planeta. Essa iniciativa por parte tanto dos Estados Unidos quanto da Europa constituiria uma verdadeira contribuição para a consolidação da paz na Terra. (p.217, grifo nosso)

Não aprofundarei comentários sobre essa passagem. A meu ver, uma resenha serve, fundamentalmente, para que o leitor tenha interesse em conhecer o livro em questão. Porém, creio que as palavras aqui expressas contrastam com uma defesa consistente e lúcida da ética e do humanismo como valores incontornáveis das relações sociais. O medo dos bárbaros: para além do choque das civilizações, é obra que valoriza e enobrece o papel político e interpretativo das ciências humanas em sua atuação desmistificadora de certos aspectos da vida social. Aqui entra a cultura, elemento-chave que permite a integração da economia, da política e do território.

Todo geógrafo interessado em geopolítica (acaso possa haver algum que não o seja?) deveria ler $O$ medo dos bárbaros. Ele nos ensina a investigar e a entender determinados discursos e motivações que conduzem grupos sociais e nações a se digladiar por recursos naturais, poder, territórios ou, simplesmente (embora não haja nada de simples nisso!), pela não aceitação da alteridade. É assim que traços e aspectos ditos "concretos" são evocados, mas que, de fato, não passam de pretextos a justificar preconceitos, julgamentos de valor, racismo, xenofobia, islamofobia...

Talvez seja essa uma das raison d'être das ciências humanas: desvendar discursos e suas reais intenções por trás de argumentos aparentemente inquestionáveis. Todorov faz isso com maestria.
Guilherme Ribeiro é professor de Geografia da Universidade Federal Fluminense (Campos dos Goytacazes).

@ geofilos@ig.com.br 